\title{
BMJ Open Familial experience of acute bacterial meningitis in children: a transversal qualitative study using interpretative phenomenological analysis
}

\author{
Elisabetta Scanferla (D) ,, ${ }^{1,2}$ Philip Gorwood, ${ }^{1,3}$ Léonor Fasse ${ }^{4,5}$
}

To cite: Scanferla E, Gorwood P, Fasse L. Familial experience of acute bacterial meningitis in children: a transversal qualitative study using interpretative phenomenological analysis. BMJ Open 2021;11:e047465. doi:10.1136/ bmjopen-2020-047465

- Prepublication history and additional supplemental material for this paper are available online. To view these files, please visit the journal online (http://dx.doi.org/10.1136/ bmjopen-2020-047465).

Received 30 November 2020 Accepted 29 June 2021

Check for updates

(C) Author(s) (or their employer(s)) 2021. Re-use permitted under CC BY-NC. No commercial re-use. See rights and permissions. Published by BMJ.

${ }^{1}$ CMME (Clinique des Maladies Mentales et de l'Encéphale), GHU Paris psychiatrie et neurosciences, Paris, France ${ }^{2} E D$ 450, Université de Paris, Paris, France

${ }^{3}$ U1266, INSERM, Institute of

Psychiatry and Neuroscience of

Paris (IPNP), Université de Paris,

Paris, France

${ }^{4}$ LPPS, EA4057, Université de

Paris, Paris, France

${ }^{5}$ Département de Soins de

Support, Gustave Roussy

Institute, Villejuif, France

Correspondence to

Elisabetta Scanferla;

e.scanferla@ghu-paris.fr

\section{ABSTRACT}

Objectives To capture the subjective experience of close family ascendants of acute bacterial meningitis survivors and to explore how they give meaning to this specific experience.

Design A qualitative study of indepth interviews using interpretative phenomenological analysis.

Primary outcome Main meaning-making processes of participants' experience.

Settings Participants were recruited through two associations of people affected by meningitis and their family ascendants.

Participants Convenience sampling of 11 women whose children or grandchildren were between 0.2 and 20 years old at the time of their meningitis diagnosis $(M=4.06$, $\mathrm{SD}=7.3)$. On average, $9.39(\mathrm{SD}=5.4)$ years had passed between the onset of illness and the interview.

Results Six superordinate themes (meningitis disease; healthcare services and professionals; knowledge/ ignorance; repercussions of the meningitis experience: 'life afterwards'; sick child attitudes/behaviour; and sibling attitudes/behaviour) and two main meaningmaking processes in relation to participants' experience of meningitis were identified: (1) the sick child becoming a 'hero': comparison with other children; and (2) engaging action/attitude: finding the 'positive' of the traumatic experience and engaging action to improve the care system. These two processes underpin the psychological adjustment to meningitis and its consequences. Conclusions This study provides a unique insight into close family members' first-hand experience with acute bacterial meningitis. Findings highlighted factors characterising the disease experience, the psychological adjustment of meningitis survivors' families and their meaning-making processes. These findings are important for research and clinical practice, demonstrating the multidimensional impact of the disease on family ascendants, their need for professional psychological support and the importance of direct involvement of parents in identifying key aspects of care.

\section{INTRODUCTION}

Paediatric acute bacterial meningitis is a lifethreatening illness that results from bacterial infection of the meninges and leaves some survivors with significant sequelae.
Strengths and limitations of this study

- An empirical qualitative method (interpretative phenomenological analysis) was used to explore the lived experience of parents and grandparents whose child or grandchild had suffered from and survived acute bacterial meningitis.

- This is one of the first studies undertaken to explore the experience of family ascendants of this condition.

- The study results may be affected by the recruitment of participants through patient association websites and by the retrospective study design (ie, reconstruction bias due to the time period between the meningitis episode and participation in the study).

- The participants were exclusively women (mothers or grandmother) and the study does not capture the experience of fathers (which is unfortunately quite common in studies dedicated to parents of children with physical conditions).

Meningococcus (another name for the bacterium Neisseria meningitidis) is one of the major causes of acute meningitis. Meningococcal infections have a high mortality rate, around $10 \%$, and a high epidemic potential. ${ }^{1-3}$

Meningococcal meningitis usually occurs in early childhood (maximum incidence in children under 5 years of age) and in young adults (under 25 years). It combines an infectious syndrome (fever, severe headache, vomiting) and a meningeal syndrome (neck stiffness, lethargy, disorders of consciousness up to a coma). Even when timely diagnosis and treatment were provided, the fatality rate still ranges from $5 \%$ to $10 \%$, commonly within 24-48 hours after the onset of symptoms. ${ }^{1}$ Bacterial meningitis may result in brain damage, hearing loss, visual impairment or learning disability in $10 \%-20 \%$ of survivors. ${ }^{4}$ A less common, but more severe (often fatal), form of meningococcal disease is meningococcal septicaemia (purpura fulminans), 
which is characterised by a haemorrhagic rash and rapid circulatory collapse. ${ }^{5}$

Given the high mortality rate and the potentially severe sequelae induced by this condition, health authorities worldwide try to foster medical research in this domain and a relevant vaccine policy. ${ }^{6}$ While major physical sequelae of childhood meningitis have been extensively studied, this is not the case for the related familial experience. When tracking empirical studies dedicated to the familial experience of this disease, we note that some articles are devoted to the issue of vaccination and the identification of potential barriers to it. ${ }^{7-9}$ In Italy, ${ }^{7}$ the Netherlands ${ }^{8}$ and the UK, ${ }^{9}$ researchers highlighted that public knowledge of meningitis and its related vaccinations improved through correct health education and effective vaccine strategies that are implemented by policymakers. $^{7}$

Besides considerations regarding vaccination policy, the literature concerning family experiences of bacterial meningitis in children and adolescents is poor. To our knowledge, there are only three studies that specifically targeted the psychological adjustment of parents experiencing paediatric meningococcal meningitis. In 2005 . Haines ${ }^{10}$ conducted a qualitative study in interviewed parents based on a Heideggerian phenomenological qualitative approach, and highlighted, among other findings, a critical need for support and understanding, as well as a need for communication, information and publicity. Comparable results regarding the provision of information about the symptoms and possible sequelae of acute bacterial meningitis and regarding the need for better communication about the treatment process and disease progression were also underlined by a more recent research. ${ }^{11}$ This latter study also focused on the parents' desire for professional support after the child has been discharged from the hospital. The psychological adjustment of parents after meningococcal disease has also been quantitatively studied in the mid and long term (3 and 12 months after discharge). ${ }^{12}$ The results indicated a risk of poor mental health among parents, with 13 of 54 mothers (24\%) and 6 of 40 fathers (15\%) scoring at high risk of post-traumatic stress disorder at 12 months. Additional studies not specific to acute bacterial meningitis also pointed at the psychological vulnerability of parents and a great need for educational support of children who have survived meningitis and septicaemia. ${ }^{13}$ One study ${ }^{14}$ targeted postintensive care syndrome in patients and families after critical neurological condition, which could include acute bacterial meningitis with neurological symptoms. This syndrome encompasses a variety of morbidities, including physical, cognitive, emotional and psychological impairments, following critical care. Taken together, these studies highlighted the psychological vulnerability of families after meningococcal disease and their need for communication and support. To the best of our knowledge, there are no French data on this question despite the severe sequelae that could be induced by the disease. ${ }^{15}$ Given the potential trauma induced by the disease and the hospitalisation, it is important to gain insight on how parents cope with this aversive event, especially how they give sense to this experience (with the possibility of a failure of this meaning-making process). Parents are the primary caregivers of these children, and the literature on 'dyadic coping' in the context of illness, a concept that refers to the stress management process in the context of couple relationship, underlined the intertwined nature of their psychological adjustment process. ${ }^{16}$ As such, the family ascendants' adjustment has a direct impact on the psychological adjustment process of the children. Indeed, better mental health of the parent is associated with better mental and physical health of the children. ${ }^{17} \mathrm{~A}$ better understanding of parents' subjective experience would make it possible to offer more assistance to the parents and satisfactory care for the children. Indeed, we already underlined the paucity of the empirical literature regarding the long-term adjustment of meningitis survivors during adolescence or adulthood in a previous research. Not only did we do so in terms of the presence or absence of symptoms but also in terms of emotional reactions, feelings, memories and meaningmaking process in the mid and/or long term. ${ }^{18}$

The objectives of the study are to capture the subjective experience of family ascendants confronted with acute bacterial meningitis, to highlight their meaning-making process in this adverse context, and to identify factors that could positively influence and develop the quality of care provided by healthcare professionals.

\section{METHODS}

\section{Participants}

This study of close family members confronted with acute bacterial meningitis was part of a broader research project dedicated to the psychological adjustment and the subjective experience of people who have experienced meningitis, either as patients or as patients' ascendants. A total of 20 participants, including 11 individuals whose children or grandchildren experienced meningitis, were recruited through two patient associations (Association Petit Ange - Ensemble contre la meningitis and Epilepsie France), thanks to a call for testimonies posted on the associations' website (see online supplemental material). The participants were not necessarily members of the association. The inclusion criteria were (1) age $\geq 18$ years at the time of the study; (2) being an ascendant of an individual who received a diagnosis of acute bacterial meningitis during childhood, adolescence or adulthood; (3) a period of at least 6 months between the onset of illness of the descendant and the interview; and (4) informed consent to participate in this study.

The exclusion criteria were (1) family ascendants who had lost their child due to acute bacterial meningitis or bereaved parents (by other cause), because the grief process could deeply affect the results; (2) severe cognitive impairment that hinders participation in the study, as 
determined by the interviewers; and (3) lack of sufficient fluency in French to participate in the research interviews.

\section{Recruitment}

The recruitment was voluntary and all participants expressed their agreement to participate in the research, according to the French ethical board's recommendations for qualitative non-interventional research. According to French legislation, collection of information on ethnic origin and religious affiliation is not allowed ${ }^{19}$ and therefore these aspects were not assessed.

\section{Ethical approval}

In accordance with Article L1121-1 of the French Public Health Code,$^{20}$ this qualitative study, which uses responses to a survey carried out by telephone from relatives of individuals who recovered from the illness more than 6 months ago, does not correspond to any of the three categories of studies falling within the scope of research involving human subjects and therefore no ethical approval was required.

\section{Procedures}

Indepth, semistructured, qualitative interviews were conducted over the telephone. Although the interviewers followed an interview guide, the participants were encouraged to express themselves freely. This guide included questions relating to the history of the disease, the current emotional state of the participant, as well as questions relating to the potential impact of the meningitis to the family and the siblings. The interviews were conducted in October 2018 by four researchers familiar with qualitative interview methods and who were trained in qualitative approaches. The mean length of the interviews was $60 \mathrm{~min}$.

\section{Analysis}

Interviews were audio-recorded and entirely transcribed. Transcripts were subsequently anonymised by removing all identifying information. The original French extracts were translated to English. A bilingual French-English researcher verified the verbatim translation to English and ensured it was consistent with the meaning of the source texts in French. Interpretative phenomenological analysis (IPA) was chosen to explore the content. For analysis of key elements, see Scanferla $e t$ al. ${ }^{18}$ ES and LF led the analysis following the principles of IPA. ${ }^{21}$ In brief, each interview was read by the first author multiple times to gain a holistic sense of participants' accounts, and discourse themes were identified by ES. The connections between the themes were then studied and the major themes were identified by the same author. Lastly, an interpretative account was produced that highlighted and analysed the experience through experiential themes and meaning-making processes. The meaning-making process is the means by which people try to make sense of their experiences, and the study of the processes of meaningmaking describes what is happening in individuals and highlights the procedural dimension beyond symptoms and outcomes. It also helps to emphasise how meningitis can be experienced in different ways by different people through the analysis of convergences and divergences in the meaning-making processes. LF audited the documentation for the first five interviews as a validity check on the analytic process. Great care was taken throughout the process to meet the criteria for scientific rigour established by qualitative analysis. ${ }^{22}$

\section{Patient and public involvement}

The scientific team/board of the project included two representatives from patient associations. They were involved from the start of the study and identified the potential psychological consequences of the disease experience. They also highlighted the interest and motivation of patients and family members to participate in psychological research, and also participated in the discussions during which questions were posed to the participants. These representatives were aware of the potential burden associated with this research and underlined on the contrary the benefits that participants could derive from the project. A press conference took place on 18 September 2020 to disseminate the results of this study on the experiences of meningitis survivors. ${ }^{18}$ The present study exploring the subjective experience of close family members of children with meningitis corresponds to the second part of the study on the experiences of meningitis survivors. In addition, we plan to organise a second conference for the association where the participants were recruited to disseminate our findings and their clinical implications.

\section{RESULTS}

In total, 11 women took part in the study, 10 mothers and 1 grandmother. The children (child/grandchild) were 3-30 years old (mean $(\mathrm{M})=13.45, \mathrm{SD}=9.37)$ at the time of the interviews, and between 0.2 and 20 years old at the time of meningitis diagnosis $(\mathrm{M}=4.06, \mathrm{SD}=7.26)$. On average, 9.39 years had passed between the onset of illness and the parent's interview $(\mathrm{SD}=5.46)$.

The participants' profile is described in table 1 .

Concerning the bacterial agent causing the disease of the child, three participants reported meningococcal, three reported pneumococcal and four reported streptococcal bacterium. For one participant, the causative bacteria was not identified, although a meningitis diagnosis had been made by the medical staff.

Six major themes emerged following the analysis of superordinates:

- Meningitis disease.

- Healthcare services and professionals.

- Knowledge/ignorance.

- Repercussions of the meningitis experience: 'life afterwards'.

- Sick child attitudes/behaviour.

- Sibling attitudes/behaviour. 
Table 1 Participants' profile

\begin{tabular}{rlllll}
\hline & Participant & Relationship to the survivor & Survivor's sex & Survivor's age at diagnosis (years) & Infectious agent \\
\hline 1 & P2 & Mother & Female & 0.33 & Meningococcus B \\
\hline 2 & P3 & Mother & Male & 17 & Meningococcus B \\
3 & P5 & Mother & Female & 0.08 & Streptococcus B \\
4 & P7 & Mother & Female & 0.75 & Pneumococcus \\
5 & P10 & Mother & Male & 4 & MD \\
6 & P11 & Mother & Female & 0.33 & Pneumococcus \\
7 & P12 & Mother & Female & 20 & Meningococcus B \\
8 & P13 & Mother & Female & 2 & Pneumococcus \\
9 & P16 & Grandmother & Male & 0.02 & Streptococcus B \\
10 & P19 & Mother & Female & 0.08 & Streptococcus B \\
11 & P20 & Mother & Female & 0.08 & Streptococcus B \\
\hline
\end{tabular}

$\mathrm{MD}$, missing data.

Further analysis also revealed several subthemes (table 2).

Only five of the above themes were selected for inclusion in this publication. These five themes were all chosen because they were directly in line with our research question (ie, the family experience of meningitis) and they were all spontaneously mentioned by the participants and did not correspond to the pre-established questions. A detailed analysis of the 'meningitis disease' (not selected theme), its physical sequelae (partial paralysis, functional disability, etc) and psychological impact (phobia, identity rearrangements, trauma, insecurity, risky behaviours, etc) ${ }^{18}$ can be provided on request.

\section{Healthcare services and professionals}

This theme includes three subthemes: (1) experience of healthcare services and care routine; (2) relationship with healthcare providers; and (3) need for psychotherapeutic support.

The overwhelming experience of an extreme situation and interactions with healthcare professionals and services were reported by family ascendants. Feelings of

Table 2 Major themes and subthemes

\begin{tabular}{|c|c|}
\hline Major themes & Subthemes \\
\hline Meningitis disease & $\begin{array}{l}\text { Symptoms (description, etc). Perception of symptoms and their evolution. } \\
\text { Diagnoses (relevance, accuracy, time, etc). } \\
\text { Description of the disease (technical words, prevalence, etc). }\end{array}$ \\
\hline $\begin{array}{l}\text { Healthcare services and } \\
\text { professionals }\end{array}$ & $\begin{array}{l}\text { Experience of healthcare services and relationships with healthcare providers (eg, communication). } \\
\text { Need for psychological support at the time of diagnosis, during hospital care and in the long term (eg, } \\
\text { rehabilitation). }\end{array}$ \\
\hline $\begin{array}{l}\text { Repercussions of the } \\
\text { meningitis experience: } \\
\text { 'life afterwards' }\end{array}$ & $\begin{array}{l}\text { Physical sequelae (partial paralysis, functional disability, etc). Relating and compensating. } \\
\text { Psychological impact and familial adjustment in the short term (coping with the possibility of death) } \\
\text { and long term (physical sequelae, medical care, daily life, school). } \\
\text { Parents coping with the illness (eg, impact on the marital couple, etc). } \\
\text { Impact of meningitis on the life course (financial and professional impact, change of life and } \\
\text { professional trajectories, 'giving up', etc). }\end{array}$ \\
\hline $\begin{array}{l}\text { Sick child attitudes/ } \\
\text { behaviour }\end{array}$ & $\begin{array}{l}\text { At the onset of the illness. } \\
\text { During hospitalisation. } \\
\text { Long-term attitudes (personality): flexibility, adaptation, courage. }\end{array}$ \\
\hline $\begin{array}{l}\text { Sibling attitudes/ } \\
\text { behaviour }\end{array}$ & Coping with the illness and its long-term effects (psychological sequelae and adjustments). \\
\hline
\end{tabular}


dismay, refusal to accept their child's life is threatened and consecutive anger came over strongly in the interviews; for many, these emotional responses triggered a request for help.

\section{Experience of healthcare services and the relationship with healthcare providers}

The experience of care services as evoked by family members varied. Some of them emphasised the quality of care.

I can't thank that paediatrician enough because he didn't know that it was meningitis yet, but he put a treatment in place (...), which saved us a few hours. (P13)

Others appreciated the attention they received at the hospital and stated that it helped them to reduce their stress and anxiety during the medical emergency situation.

We were very, very welcomed, they arranged a room for us at the hospital. It was a special room for the parents so we could sleep there the first night. (P11)

Family ascendants praised both the technical and relational skills of healthcare providers. However, within the narratives, there also appeared areas of dissatisfaction, such as the long waiting time before receiving the diagnosis, the complexity of care received by their loved ones and the hospital environment in general.

After she got there, we waited for three or four hours without hearing from her. It was really a very, very long wait, no news, no nothing. (...). And then they put us in a very creepy office. It wasn't reassuring at all (...). (P20)

It appears here that it is not so much the wait itself that is stressful, but rather the absence of communication with the healthcare providers and especially the absence of news concerning the state of the child. This leads us to approach the following subtheme of communication.

Indeed, there were many occurrences which highlighted the difficulties in communication with healthcare professionals. The dialogue was perceived as difficult and generated frustration.

The doctor came in and he got angry with me and told me I had to stop my show (...) he thought I was a crazy person who was there to bother them. (P10)

This mother perceived here a lack of consideration for her emotional distress, which is misjudged by the physician, according to her testimony. We found the perception of this lack of consideration in the testimony of another study participant who mentioned that professionals gave little credit to her opinion:

In any case, the way they told us things weren't right at all... Insinuating that it was not justified to come and take her [to the hospital], when in the end the (positive) results proved it the next day. (P19)

Several mothers highlighted that the information they provided about their unwell child and their intuition of the seriousness of the situation were not considered. Therefore, they often felt discredited by the medical professional and expressed their frustration.

I got angry (...), I told him that my daughter had had ear infections before, but that it hadn't put her in this state of drowsiness, with vomiting and a fever that wouldn't go down (...). I insisted, and he told me I was a hysterical mother. (P13)

Some family ascendants remembered making harsh comments to certain doctors whose attitude or behaviour was deemed to be disrespectful, inappropriate or dismissive.

I told them, "We're not numbers" (...). There's even a doctor for whom I asked that he no longer treat my daughter. I even notified the hospital management, so he was replaced by another doctor. (P2)

This mother placed herself as 'guardian' of her child in order to protect her son and to have him considered as an individual (and not as a 'simple number').

\section{Need for psychological support}

The parents showed very intense emotions when confronting the different stages of illness. Their emotional response oscillated between uncertainty and frustration, and fear, anxiety and shock as a result of what they sometimes perceived as a 'cold' and 'hard' relationship with healthcare professionals. They stressed the need for psychological support to help them at the time of diagnosis and intensive care, especially when they felt overwhelmed.

I had a very bad experience at the ICU because I found that the staff... well, I think they're people who see this every day and have to remain impassive before certain situations. But we, as parents, we need accompaniment, we need support, we need help, and that's not necessarily what we had. (P2)

This parent interestingly gave a contrasting description between the 'distanced' functioning of intensive care unit (ICU) professionals, a function that she understands, and her own needs as a mother.

Moreover, family ascendants experienced difficult emotions in the long term as well during their children's rehabilitation period.

They referred us to a psychologist. That's good in itself but it often happened in the hospital room with our daughter next door, so it wasn't necessarily the right time, we were very emotional. It was good to see a psychologist when our daughter was hospitalised, but we had very long medical visits for L., (...), 
but afterwards, we were abandoned to ourselves, we weren't supported at all. (P5)

Here, this mother indicated that the reference to a mental health professional was not always sufficient. The time and the clinical frame of psychological support were also critical, and despite this professional support she felt abandoned.

For some, the help of professionals was essential in the process of alleviating their sense of guilt and making sense of the traumatic experience of accompanying a child who was experiencing meningitis.

I started a behavioural and cognitive psychotherapy with a psychologist so that I could convince myself that it's not my fault that my daughter had purpura and was amputated. (P2)

Cognitive-behavioural therapy and especially cognitive remediation are specific techniques used in cases of particularly distressful thoughts.

\section{Knowledge/ignorance}

This second theme includes three subthemes: (1) the disease; (2) the unpreparedness of healthcare professionals/experts; and (3) the familial caregivers' helplessness.

Unanimously, the interviewed parents focused on the importance of knowledge about acute bacterial meningitis, including its symptoms and possible sequelae, as well as the treatment process and disease progression. The testimonials stressed the parents' own need for understanding on the one hand, and the healthcare providers' knowledge about the disease on the other hand, which they sometimes perceived as insufficient. The lack of communication, information and support for families was also highlighted.

\section{About the disease}

The main part of the interviews highlighted that knowledge about meningitis was key and many participants expressed the need to develop this knowledge, as most of the time the disease was totally or partially unknown before it affected their child.

I didn't even know what it was. I didn't even know there were three forms of meningitis; I didn't even know what "purpura fulminans" was (...). I'd never even heard of it. (P2)

Meeting this need to better understand the disease involved the acquisition of a scientific background and the ability to express it with technical medical vocabulary. Therefore, many of the participants needed to acquire some form of expertise on the disease to learn the means and modalities of infection. They widely stressed that the internet and patient associations were a valuable source of knowledge.

I've done a lot of research on the Internet, I've read testimonials and a lot of things. I contacted associations that receive amputees and do a lot of things for them. I talked on the phone with people from these associations who also reassured me a lot (...). I wanted to find out as much as possible. It helped me a lot to be able to manage the situation as well as possible. (P2)

Developing some forms of expertise on the disease and taking an active approach to it were reported as key aspects.

I didn't realize how the infection is transmitted or the difference between viral and bacterial meningitis. But now I'm a meningitis expert (...). (P5)

I've done a lot of reading on the subject, and the first reflex you have when you have a medical team in front of you that gives you a flood of information without taking the time to use words that are accessible to everyone, you have to check it out (...). (P5)

Having an active approach to learning about the disease probably compensated for the perceived passive attitudes of healthcare professionals and the perceived lack of support that parents experienced during their child's care.

For some participants, their understanding of their child's potential situation contrasts with the expertise of the healthcare providers.

\section{Perceived unpreparedness of health professionals/expertise}

In several cases, patients were given alternative diagnoses, suggesting an imprecise understanding of the symptoms and/or inadequate responses by healthcare professionals.

When I was told that she had the germ of streptococcus, I consulted the Internet and saw that it could cause meningitis (...) The paediatrician told me: "Don't worry, (...) she was treated and you will never hear about it again... there's no chance of that happening", ... a week later, hospital, emergency room, meningitis. (P20)

This mother underlined here some diagnostic wandering; despite words full of assertiveness advising her not to worry, what she dreaded effectively happened.

In other cases, healthcare providers seemed completely overwhelmed by the emergency context and did not fully perceive the seriousness of the symptoms.

When I called [the emergency services] for the relapse and told them that she had been out of hospital for 15 days for meningitis and that she had all the symptoms again, they didn't want to send us someone (...) Then the doctor (...) told us that we were really not very recommendable parents and that we should only call for real emergencies instead of calling for a little girl who is crying because she has a little fever. (P19) 
Helplessness of familial caregivers

The experience of a lack of responsiveness on the part of healthcare professionals caused frustration and feelings of helplessness in the patients' families. They also stress that some diagnoses are shocking and that physicians should be cautious in the way they phrase them as their diagnosis might be contradicted by the favourable evolution of the disease.

When they [the doctors] tell you that your child has a life expectancy of fouryears, when she reaches five years, you think that they may need to reconsider the diagnosis.... (P5)

The participants' narratives also emphasised the importance of public awareness of meningitis and the role that patient and carer associations play in this regard. Associations provide families emotional and psychological understanding and support, which significantly helped the family ascendants through the stressful events they were experiencing.

I think it's a disease that isn't adequately known. When she was at the hospital, I was seeking answers to my questions and I searched on the Internet, and that's when I came across the website of [name of the association]. Thanks to this website and the persons who foster it, we learn everything that can happen around meningitis. I tell myself that if people were better informed about the symptoms, more lives could be saved. (P19)

Taken together, the testimonials highlighted the psychological vulnerability of families and their need for communication and support.

\section{Repercussions of the meningitis experience: 'life afterwards'}

This major theme integrates five subthemes: (1) physical sequelae; (2) psychological impact; (3) parents coping with the illness (in the short and long term); (4) impact of meningitis on the life course; and (5) meaning given to the extreme experiences they have gone through.

\section{Physical sequelae of the child}

Most of the interviews revealed the negative impact of meningitis on the health of their children and grandchildren, and in particular the significant physical and cognitive sequelae associated with meningitis, including partial paralysis, heart problems, and hearing and visual impairments. These impairments significantly limited survivors' ability to function in an autonomous manner and caused daily distress and frustration to the whole family.

(...). The definition is global psychomotor impairment, with a significant language deficit. Not long ago, it was absence of language. You have to understand that (her) brain doesn't work on its own (...). Today, she has the entire left hemisphere that is necrotic, she has frontal and lateral lesions on the cortex which is between the two hemispheres. So, it's all been damaged. (P5)
Some testimonies focused on the physical impairments and a sense of permanent loss of prior abilities of their child, which caused them to develop feelings of injustice.

These are diseases that totally destroy the life. She was a little girl who was $91 / 2$ months old, who was beginning to walk, who was very lively, and she was completely stopped in her stride. It's really an injustice. (P7)

\section{Psychological impact and familial adjustment}

Besides the negative physical and cognitive impact of the disease on their relatives, the participants also strongly insisted on the psychological impact of meningitis, and in particular the state of shock that they experienced during the period of hospitalisation.

I was holding him in my arms, and I was looking for a way to comfort him. (...) I was just very, very anxious (...). I was completely shocked by his condition. I thought he was dying. In fact, I know he barely avoided death. I've always felt that my son was close to death. (P10)

The sight of the body of the diminished child, bearing the scars of the disease, was intolerable. Most of the participants described an impression of imminent death, which is terrifying. A grandmother mentioned this fear, which she states sometimes still comes to her.

What's more, he was in great pain and that's really what shocked me the most. I've never seen anyone suffer like this, especially not a child. Three years later, I'm still shocked by it. (P16)

Some mothers stressed the traumatic nature of the experience of facing the danger of death of their child, especially during intensive care. The emotions described by most of the narratives are intense and vary between denial and deep anguish, some even evoking a state of stupor.

When the doctor came to see us, she was still in a life-threatening prognosis. He told us that (...) there were three possible outcomes. Either she was not going to make it, or she was going to make it, but he was not able to say whether she will breathe on her own or not, or she was going to make it, but she will be very severely disabled (...). For me, none of the options were possible. (P20)

Other testimonials illustrated the parents' aptitude in managing the exceptional situation and staying positive in front of their child during the hospitalisation.

Nevertheless, we had the chance (...) to keep hope alive. When we went to see her (...) in the intensive care unit, we talked to her, we sang songs to her. Even if we didn't know if she could hear us, we kept in mind that we had to stay positive. (P11) 
However, most of the respondents commented on the long-term severe psychological consequences of the meningitis experience and sequelae. They described their global psychological vulnerability, and for some of them depressive symptoms requiring treatments.

I had nothing left to hold me. Everyone around me was happy, but I wasn't. I couldn't explain it, nothing had taste (...). I wanted to kill myself... but at the same time I told myself that those who remained would be too sad... so I didn't do it. (P12)

The descriptions of depressive symptoms, including anhedonia and suicidal thoughts, were at times mixed with the perception of relief and happiness, often leading to a feeling of isolation.

The time necessary to regain personal and family balance also emerged as a common issue.

After the first six months, I got the backlash. I tried to put up with everything, telling myself that I was strong. My daughter was strong, so I had to be strong. At one point, (...) I fell into a deep depression that lasted for two years. I was on medication, anxiolytics and antidepressants to get me out of this hellish spiral. I saw everything in black and I told myself that my daughter would never make it, that they would make fun of her and that life would be difficult for her. I locked myself in a negative bubble. Now I'm a little better, but there are always times when I think about the future, and I still have fears and anxieties about what might happen later on. (P2)

In these two testimonies, we can notice the lasting concern for their child, even when they progress to adulthood. This concern is permeated with anxious anticipation concerning the survivors' well-being.

\section{Parents coping with the illness}

Having to take care of a child who is often severely impaired is an ordeal for the parental couple. However, most of the interviewees highlighted that, despite occasional tensions, they managed to deal with this difficult situation.

Concerning my couple, we have always remained very close together. My husband is always very, very present. (P11)

Along with the family, in many cases the partner is identified as a valuable source of mutual support in the moments of doubt. The family, as a whole, is described as an important source of support.

Luckily, we have a big family that never gave up on us. They took turns coming to see us. Every day, we had someone to support us. (P13)

The quality of the relationship and communication of the two parents resulted in new forms of adjustment beyond the effects of the disease and brought new perspectives to family life.
We complement each other (...). We talked about it [the meningitis experience] afterwards and we thought we'd done really well. (P20)

The notions of complementarity and open communication appeared to be critical in coping with the disease and its multiple impacts.

\section{Impact of meningitis on the life course}

Caring for a child with a disability takes time, requires careful planning and often has a serious financial impact on the family, as underlined by the interviewed parents.

I think it's all about her. For one thing, there are all her medical visits since she was four months old. There are 3 to 4 appointments a week, on top of work, you have to run around and it's still very heavy. (P20)

Most of the time the disease and its consequences involved changes in the professional trajectories of the survivor's close family and in the whole family's way of life.

At the time she was ill, I had planned to return to work (...) But I never went back to work, I didn't honour the contract. Then, for 6 years, I didn't work at all because (she) needed me, I was all the time with her, going back and forth for medical appointments. It was very complicated. (P11)

These words showed that besides psychological impact, caring for a child affected by acute bacterial meningitis also has a financial cost, even in a country like France where social assistance is present.

Finally, some participants underlined the positive impact of maintaining professional activities not only for financial reasons, but also as a way to facilitate a social life beyond the world of disability.

This job allows me to get out of everything related to disability, nappies, housework. It makes me think of something else, and it makes me earn some money. (P7)

Adjustments also concern material aspects such as the person's living and housing and the practical organisation of the child's care. They are necessary to allow the family to find a new form of everyday functioning.

The house is being rearranged to create a room on the ground floor. Until now, she had been going upstairs, but we hope that when she has a room on the ground floor, it will be easier to find someone to relieve us so that we can leave from time to time. (P7)

If her behaviour is definitely related to meningitis, it is a real handicap for us in many ways, we can't go anywhere, it is really difficult. We try to show her many things so that she can continue to improve but taking her to a zoo or a park is a real challenge. (P20) 
Thus, usual leisure activities for many children become extremely complex to organise: everyday life is often marked by renouncement.

The interaction with the health services administration regarding the coverage of the family member's care is also a concern mentioned by family ascendants. They emphasised that the complexity of the administrative procedures and the constant need to prove legitimacy to their request constitute a considerable psychological burden in addition to the burden of caring for the meningitis survivors.

I always say the biggest handicap is administration. (...) you have to keep fighting. (P7)

The energy expended is considerable, and participants often use sports comparisons or fighting metaphors to describe their daily life.

We always have to go running around, putting together files, emails... I think that is the worst. (...) When we had a renewal [of the disabled adult allowance file], and they stripped us of everything. We had to appeal. On top of that, they always take 6 months to respond... we spend our time fighting. (P20)

\section{Sick child attitude/behaviour}

Several testimonials described the positive evolution of the children who have survived meningitis and stressed in particular the progress they have made and the skills that they have acquired, frequently reaching levels of results that go beyond what the healthcare professionals considered possible.

When we see the MRIs, compared to the damage she has to her brain, the doctors don't understand that she can do what she does (...). For them, in relation to her lesions, she should be in a vegetative state, while she can eat by herself, she walks alone with her armchair, she sings, she loves to sing, she loves to play, music, early learning games, etc. (P13)

Some individuals also evoked the adaptability, flexibility and courage of their loved ones.

I think she's happy, but she has her ups and downs (...). She tries, she finds ways to do it (...). She has great strength of character and now she wants to do things even if it's hard for her. (P11)

And in the end, she has made up for her developmental delay (...). She has caught up with everything and even the attending doctor told me that she is amazing. She really is a great little girl. (P19)

Furthermore, many testimonies referred to the social abilities of the meningitis survivors and their capacity to enjoy a satisfactory quality of life despite the limits imposed by the severe handicaps they experience.

She's very sociable, so she's a bit of a mascot everywhere she goes. As she is very charming, very attaching and very funny, she doesn't have too many problems adapting to a new environment. (P5)

The child's ability to forge links with her/his peers and her/his 'zest for life' are very often underlined.

Despite the disability and limitations brought on by the disease, the survivors' ability to bounce back and adjust is stressed with admiration by the participants. However, the experience of an event that suddenly and unexpectedly upsets the life of the whole family also required the siblings' capacity for psychological adjustment.

\section{Sibling attitude/behaviour}

The experience of acute meningitis disease and its sequelae is a stressful experience for the whole family, not only when a family member is admitted to the ICU, but also in the mid and long term. Within this study, parents focused on the siblings of the sick child, as they also experienced some form of impact or disruption as a result of their siblings' illness.

A common thread among the interviewees was the parents' perception of the attitude and behaviour of siblings towards the meningitis survivors. Many participants could mention the supportive way in which the siblings coped with the disease and their positive role in the recovery and life trajectories of their loved ones.

I am convinced that it is thanks to her twin sister who has been a great stimulant for her. She has caught up with everything. (P19)

Likewise:

I think his brother was really a driving force, even if it's not always obvious to him. (P5)

Particular emphasis is also placed on the siblings' ability to understand, help and protect their survivor sibling.

He tells us: "You don't understand that she wants that!" We didn't understand fast enough, according to him, and he was interpreting. (P5)

The brother here adopts the function of intermediary or more precisely as an interpreter between his sister and their parents, revealing a rare complicity.

He's a child who's very protective of his sister. He doesn't hesitate to go and see the other children in the schoolyard if his sister is being teased. (P2)

The role of a 'guardian' that we evoked when speaking of parents can sometimes be taken by a brother or a sister of the sick child as well.

In addition, parents stressed that overall the daily confrontation with disabilities enabled the siblings to develop a sense of openness and tolerance of other people's differences.

My daughters have a lot of empathy, whether with their [disabled] sister or with other children. It's true that they also have a different life. It is very enriching for them, because they know the difference, they 
learn the values of life, which not all children will necessarily have... (P7)

However, the testimonies of some other participants highlighted the psychological impact on the siblings of the specific disease-related environment and the responsibility that they assumed. Possible mentioned causes include the fact that the disabled child monopolised the parents' attention or that the place and role of everyone in the family may be affected.

Our second [daughter] is everyone's elder sister. She says it all the time: "By age, I am her little sister, but in my head I am her big sister...". (P13)

Finally, he has developed obesity (...). He was deeply shocked and traumatised by his sister's amputation (...), he's aware that his sister is different from other children. He assigned himself the role of the big brother, which is: "I'm here, I'll protect you, I'm here for you (...)", he took his role very seriously. (P2)

The representation of this mother is clear: she sketched a linear causality between the amputation of her daughter, following meningitis, and the obesity of her son, whom she considered traumatised.

Despite the severity of the illness and the magnitude of its consequences for the survivors and the whole family, the narratives stressed that in the long term one of the key elements of balance is the parents' ability to ensure a family life is 'as normal as possible' for all siblings, where everyone (re) discovers his or her place.

\section{Narrative account and profiles of meaning-making}

The analysis of the above-mentioned themes allowed for the identification of the meaning-making processes deployed by the participants and which are reflected in their remarks. These two processes underpin the psychological adjustment to the meningitis and its consequences.

\section{Comparison with other children: the sick child becoming a 'hero'}

In order to have reference points on the development of their child, some of whom are affected by serious sequelae, many parents compared the latter with other children in their family circle. This comparison often turned out to be a source of great distress, by noting how much the child is disabled and behind in their psychomotor development. For instance:

I have a lot of children in my family, and I could see that for her there were some things that were wrong. (P5)

Thereafter, she evolved very slowly compared to children of her age. (P11)

In some cases, the comparison did not come from the parents themselves, but from a stranger.

One day, our kid was 5 years old, she was in her stroller with a pacifier in her mouth, one couldn't see that she was disabled, and there was an old man who approached us saying: "look at my little grandson, he walks, he is not in a stroller and he does not have a pacifier, yet he is younger!" ( $\mathrm{P} 7)$

This mother highlighted the perceived violence born from this comparison imposed by a stranger who knew nothing of her history.

Other parents insisted on the developmental similarities between their child, even when disabled, and other children of the same age:

Otherwise, in terms of development, she is a child like any other (...). She makes a point of doing the same activities as other children. (P2)

We found a similar statement in the testimony of a grandmother:

[He] does everything like them (his siblings). He is a child who has his place among the siblings, there is no problem. (P16)

Some parents expressed pride in having managed to cope with such an extreme experience, as an individual and as a couple.

It [the meningitis experience] gave me that attitude because I wasn't like that before. It gave me a stronger temper to come with it. (...) It's ok to break down, you have to break down at some point, but the next day I am back on top, and I'm back on my feet.... (P13)

Another mother evoked the support she found in her relationship with her partner.

I see many couples (...) who split up because of their child's disability. However, we supported each other, we didn't argue, there were no conflicts related to that. No, we did well. (P20)

However, above, the parents' pride was centred on their sick child. We found in their speech a highlighting of her/ his exceptional character. As mentioned earlier, several participants expressed a sense of satisfaction about their child's trajectory. Some insisted on the fact that they initiated certain attitudes, instilling courage in their child.

She's a little girl who's doing very well, we've done everything we could. She likes to be assisted, so we taught her that no, that wasn't life, she had to do it on her own. (P19)

For some family ascendants, their loved one was in a way revealed in the disease, without the family having anything to do with it. The 'hero figure' then becomes the one that best describes their child. 'Hero', because the child is distinguished by her/his bravery, her/his exceptional abilities. So this mother told us about her daughter:

That's when I saw that my daughter was a fighter, because after waking up alone from a coma, she saw me and said "mama", at 4 1/2 months. She spoke. She 
woke up from a coma, looked me straight in the eye and said "mama". (P2)

Faced with an extreme experience-the mother insisted that her daughter was close to death-the child's exceptional character was revealed in her verbal precocity. Furthermore, it is within the mother-daughter relationship that the extraordinary capacity of the child emerged.

These exceptional capacities mentioned by family ascendants can thus be physical, as in the testimony mentioned above, or in the words of other parents:

She has a phenomenal strength in her arms that she has developed due to the absence of her legs. (P13)

A physical force, therefore, but also a psychological one:

(She) turns out to be a very combative little girl. (P5)

It appears that this revelation of the heroic character of their child allowed parents who perceived this extraordinary dimension to find a positive meaning in this painful experience.

It is one of the most beautiful moments that I experienced in this terrible ordeal (...). At the beginning, the doctors didn't believe us (about the fact that their daughter was able to speak) and we rang them to show them. We even kept photos of those moments. For us, it was a magical moment because we realized that our daughter really wanted to live. (P2)

We find here the characteristics of extraordinary events, which even look like a miracle for these parents. The fact that there are people who do not believe, who must therefore be convinced; the need for proofs, the fight that was carried out and the ultimate meaning of this fight: the revelation of a will to live. This elaboration of the figure of the child as a hero thus made it possible to give a positive meaning to this painful experience, and further it may confirm the meaning and value of the child's life.

This mention about finding positive meaning through the distressful experience of meningitis leads to a second meaning-making process: engaging action to improve the healthcare system.

Finding the 'positive' of the traumatic experience and engaging action to improve the healthcare system

The discourse of the participants echoed a desire to take an active position in their relationship with the disease, not only through the acquisition of personal knowledge about meningitis, but also through the commitment to raise awareness of the disease in the general population. This commitment can also concern awareness-raising work about people with disabilities. For instance, this mother told us:

I raise awareness among children and young people on the concept of disability. I go to schools or associations with a small booklet that I made, and I explain to children what disability is, to remove taboo words and so that they put words on the little friends who are dyslexic, or in a wheelchair, or mentally handicapped, etc. (P7)

Believing that in France individuals are not familiar enough with difference-here linked to a disability — this mother wanted to suggest to the youngest people to think about the inclusion of their disabled peers so that they can have a life as normal as possible.

This engagement process, which allows for them to feel active instead of enduring the vagaries of life as a parent with a child with serious sequelae always, starts from the intimate experience to try to improve things for the greatest number. Thus:

We got a family house and we are in the process of renovating it to make a home to accommodate disabled people on vacation in the Alps (...). It was our dream for us, so we are doing it for others. (P7)

Having been confronted with major difficulties relating to the accessibility for disabled people in many vacation homes, this family decided to take matters into their own hands and create this dedicated and accessible place. The form of altruism that this commitment constitutes can also be noted, which is why many, especially within the family, admire this commitment. Thus, the grandmother of a child who suffered from meningitis testified to her admiration for her daughter, the mother of this child.

My daughter invests in everything, in everything, for her little son It's extraordinary. (P16)

\section{DISCUSSION}

This study on the experiences of close family members of meningitis survivors highlighted six themes, shared by most of the participants, and two meaning-making processes that appeared through the analysis of the narratives. The qualitative findings stressed the parents' understanding about acute bacterial meningitis and their relationships with the care system and the healthcare providers, and they also highlighted the ignorance about this disease at the time of medical treatment, both their own and those of certain healthcare professionals. In contrast, they spoke of the knowledge that they had been able to acquire through patient associations. Much of their testimony dealt with the multidimensional repercussions of the disease on their sick child and for the whole family. The attitude and behaviour of the child affected by meningitis were largely described and often glorified. Finally, the reaction of the siblings was a matter of concern for many interviewed parents.

These qualitative results provide insight into the nature of the mid-term and long-term repercussions of the disease at an individual and familial level; they also offer an understanding of the distress induced by these impacts. Indeed, consistent with previous quantitative studies, ${ }^{12} 13$ this research stressed the psychological 
burden associated with being the family of a child affected by acute bacterial meningitis. This burden is imbued with traumatic elements (confrontation with the possibility of the child's death, awareness of the possible sequelae) and is experienced daily by families who have to face medical, economic and societal challenges. The present results also underline the expressed need for specific and professional support in this population. The interviewed parents insisted on their requirement for psychological support, not necessarily during the acute phase of the hospitalisation, when they were often stunned and preferred to be constantly at the bedside of the sick child, but rather at hospital discharge and in the long term, when they understood more clearly what their life would be like after this disease. A recent article showed that coping support interventions are effective in improving parents' anxiety and stress symptom burden related to acute paediatric hospitalisations. ${ }^{23}$ Structured interventions could indeed be offered to parents of children affected by meningitis during hospitalisation and at discharge.

However, the parents interviewed in this study not only experienced distressful challenges induced by the illness of their children but also, for some participants, trajectories of post-traumatic growth. Tedeschi and Calhoun ${ }^{24}$ define 'post-traumatic growth' as any positive personal changes that occur after experiencing a potentially traumatic event. The meaning-making processes analysed in this study indicated such a trajectory. The parents' pride in their child and the pride that some admit feeling about themselves because they are satisfied with the way they take care of their child and their family echo this growth process. A mixture of vulnerability and growth was underlined in a previous qualitative study, conducted among mothers whose school-aged children were born extremely prematurely; just as several participants of our research, these mothers celebrated their children's success. ${ }^{25}$ The celebration of children's skills and their ability to overcome their disabilities becomes for certain participants the depiction of a hero trajectory, which may be related to the dimension of 'post-traumatic growth', such as 'new possibilities' and 'appreciation of life'. ${ }^{24}$

Furthermore, the involvement of some parents in patient associations, even their participation in this study, may indicate the experience of 'new possibilities' and 'enhanced relationships'. Highlighting this growth in some individuals should not lead to an 'injunction to resilience' but to the observation that the close family members of meningitis survivors can adjust to this difficult experience and find meaning in it.

\section{Strengths and weaknesses of the study}

This study has several limitations. The first limitation is related to the nature of the recruitment and the representativeness of the sample. As participants volunteered to take part in the research, this may have resulted in selfselection bias. Therefore, findings may reflect the views of people more interested in taking an active approach to the disease through engagement with a patient association. Moreover, the sample exclusively consisted of adult women (10 mothers and 1 grandmother). Thus, this study might not be representative of the wider spectrum of close family members who faced the meningitis disease. In future studies, a more diverse sample, including male participants, recruited from a plurality of treatment facilities and setting contexts of care, would be preferred and provide a complete map of the meanings attached to subjective experiences and the generalisation of the study findings. This would allow for examination of whether different experiences would be described and would provide a complete map of the meanings attached to subjective experiences and the generalisation of the study findings.

A second limitation concerns the retrospective nature of the interviews. This wide time period could have induced recall and reconstruction bias in the material (eg, negative aspects often tend to be better remembered than the positive ones). A worthwhile direction for future research might be the exploration of the subjective experience of parents confronted with acute bacterial meningitis and the family members' psychological adjustment shortly after the acute phase. A longitudinal design would also allow for capture of differences in their adjustment of variations in the psychological adjustment of the study participants.

Despite these limitations, this is the first study to use a validated methodology to provide insights on the lived experiences of families that have faced bacterial meningitis disease, and it highlights several meaning-making processes of this life-changing experience. It stresses on the one hand the interviewed parents' need for improved communication with the healthcare providers, and the importance of an increased knowledge surrounding the disease on the other hand, in particular with regard to the basic education of the public in general and the diagnostic competences of primary care providers in particular.

\section{Clinical implications}

The findings in this study highlighted several dimensions that could be of clinical relevance, such as the following:

- The value of the intervention of experts in the field of infectious diseases in the continuing professional development of physicians, which would improve not only their familiarity with meningitis and its treatment, but also their capacity to interact with carers in the most appropriate and efficient way. ${ }^{18}$

- The mismatch between family members and healthcare professionals during the onset and course of the meningitis, as well as its management in healthcare facilities that should be given attention. A promising avenue for improvement, both from a research perspective and from a clinical standpoint, is the integration of expert patients into care procedures and into the training curriculum of healthcare professionals.

- The disease-related environment and more specifically the experience of accompanying a child 
receiving intensive care and the related risk of death are stressful and may potentially result in some disruption or trauma for the whole family. Being regularly informed of the care provided to their child, taking an active part in it and receiving attention from healthcare professionals are mentioned as mitigating factors that help alleviate stress and anxiety. Several authors have emphasised the positive impact of family open visitation and parental presence for the care of their child, especially in emergency care settings and ICUs $^{26-28}$; impacts include relieved anxiety and fear, as well as reduced psychological distress and postintensive disorders, for both the family members and the survivors. ${ }^{29}{ }^{30}$ While this open visitation is more and more widespread in France, sometimes this is not made possible due to lack of human resources (professionals to support families) and of available premises. One specific aspect related to family presence during ICU procedures is the siblings' visits. As in other contexts of severe diseases, sibling visitation is being increasingly endorsed as a positive development in patient care. This is relevant especially because it facilitates elaboration of the siblings' own perception of the situation and prepares postdischarge life, reduces fantasies, increases understanding and sense of control over the situation, increases bond enhancement, and improves communication between families and care providers. ${ }^{273132}$ Thus, the implementation of experimental initiatives in the context of bacterial meningitis intensive care seems desirable. Collaboration between different healthcare providers (clinicians, nurses, psychologists) and parents in order to create appropriate visitor conditions and organisation of staff is strongly supported by the literature. ${ }^{29} 3334$ Given the paucity of research on this issue, further studies on the psychological impact and implications of the siblings' presence in ICUs could offer some insights on how they cope with this adverse event at the time of care and in the longer term. In this perspective, exploring the siblings' experience of the disease would provide a better understanding of the meaning-making process and could help identify potential pitfalls where there is a need for sustainable psychological assistance.

- The need for continuing efforts to consider and monitor the emotional burden of the disease on the child's family ascendants, the psychological adjustment process and the family's trajectories over time. In this regard, it would be valuable if family ascendants of acute meningitis survivors could benefit from systematic and, when necessary, professional consultations during and after their experience of the disease. The more appropriate forms and timing of this support, prognostic factors and outcome merit further investigation.

\section{CONCLUSIONS}

This study helped to capture the subjective experience and psychological adjustments of parents confronted with paediatric meningococcal meningitis. Two main meaning-making processes in relation to participants' experiences of this adverse context emerged from their discourse. These processes emphasised the importance of information and support of families, the potentially traumatic impact of the illness experience, and the possibility of post-traumatic growth for some individuals, including the desires of parents to engage in improving the care system. Providing family ascendants with accurate information about their child's conditions and treatments, as well as involving them in the care and medical decisionmaking, could positively influence and develop the quality of care provided by healthcare professionals.

In the mean time, clinicians, caregivers and other stakeholders of the healthcare system should be aware that information and the involvement of the family as an active partner in the care process are conditions for its effectiveness, from the onset of disease symptoms, to their management in the emergency rooms and throughout the journey of recovery.

Correction notice This article was published with an error. The author name Philip has been updated.

Acknowledgements The authors would like to thank all the meningitis experts (Patricia Merhant-Sorel, president, Association Petit Ange - Ensemble contre la meningitis; Christophe Philippe, paediatrician; Catherine Weil-Olivier, paediatrician; Myriam Winance, sociologist) for participating in the development of the interview guide and their useful comments during the development of this study. They also would like to thank Véronique Loncle-Provot and Céline Pribil for their support and valuable contribution to this manuscript. Finally, the authors would like to thank Edusanté for interviewing the participants.

Contributors ES and LF conducted the review of the literature. ES was the main coder for the thematic analysis. LF was the second coder for the thematic analysis. $\mathrm{ES}$ and LF analysed the data and edited the manuscript. PG contributed to the construction of the research project and supervised the discussion of the results. All authors read and approved the final manuscript.

Funding The discussion with experts, the qualitative study, its analysis and the writing of the manuscript were funded by GlaxoSmithKline Biologicals.

Competing interests None declared.

Patient consent for publication Not required.

Provenance and peer review Not commissioned; externally peer reviewed.

Data availability statement Data are available upon reasonable request to $\mathrm{e}$. scanferla@ghu-paris.fr.

Supplemental material This content has been supplied by the author(s). It has not been vetted by BMJ Publishing Group Limited (BMJ) and may not have been peer-reviewed. Any opinions or recommendations discussed are solely those of the author(s) and are not endorsed by BMJ. BMJ disclaims all liability and responsibility arising from any reliance placed on the content. Where the content includes any translated material, BMJ does not warrant the accuracy and reliability of the translations (including but not limited to local regulations, clinical guidelines, terminology, drug names and drug dosages), and is not responsible for any error and/or omissions arising from translation and adaptation or otherwise.

Open access This is an open access article distributed in accordance with the Creative Commons Attribution Non Commercial (CC BY-NC 4.0) license, which permits others to distribute, remix, adapt, build upon this work non-commercially, and license their derivative works on different terms, provided the original work is properly cited, appropriate credit is given, any changes made indicated, and the use is non-commercial. See: http://creativecommons.org/licenses/by-nc/4.0/. 
ORCID iD

Elisabetta Scanferla http://orcid.org/0000-0002-6985-6662

\section{REFERENCES}

1 Center for Disease Control and Prevention (CDSC). Bacterial meningitis. Available: https://www. cdc. gov/ meningitis/ bacterial. Html [Accessed Aug 2020].

2 Omoleke SA, Alabi O, Shuaib F, et al. Environmental, economic and socio-cultural risk factors of recurrent seasonal epidemics of cerebrospinal meningitis in Kebbi state, northwestern Nigeria: a qualitative approach. BMC Public Health 2018;18:127-36.

3 Lingani C, Bergeron-Caron C, Stuart JM, et al. Meningococcal meningitis surveillance in the African meningitis belt, 2004-2013. Clin Infect Dis 2015;61 Suppl 5:S410-5.

4 World Health Organization. Retrieved on :. Available: https://www. who.int/gho/epidemic diseases/meningitis/suspected cases deaths_text/en [Accessed May 2020].

5 Brouwer MC, Tunkel AR, van de Beek D. Epidemiology, diagnosis, and antimicrobial treatment of acute bacterial meningitis. Clin Microbiol Rev 2010;23:467-92.

6 Greenwood B. Editorial: 100 years of epidemic meningitis in West Africa - has anything changed? Trop Med Int Health 2006;11:773-80

7 Morrone T, Napolitano F, Albano L, et al. Meningococcal serogroup $B$ vaccine: knowledge and acceptability among parents in Italy. Hum Vaccin Immunother 2017;13:1921-7.

8 van Lier A, Ferreira JA, Mollema L, et al. Intention to vaccinate universally against varicella, rotavirus gastroenteritis, meningococcal $B$ disease and seasonal influenza among parents in the Netherlands: an Internet survey. BMC Res Notes 2017;10:1-6.

9 Jackson C, Yarwood J, Saliba V, et al. UK parents' attitudes towards meningococcal group $B($ MenB) vaccination: a qualitative analysis. BMJ Open 2017;7:e012851.

10 Haines C. Parents' experiences of living through their child's suffering from and surviving severe meningococcal disease. Nurs Crit Care 2005;10:78-89.

11 Sweeney F, Viner RM, Booy R, et al. Parents' experiences of support during and after their child's diagnosis of meningococcal disease. Acta Paediatr 2013;102:e126-30.

12 Garralda ME, Gledhill J, Nadel S, et al. Longer-term psychiatric adjustment of children and parents after meningococcal disease. Pediatr Crit Care Med 2009;10:675-80.

13 Clark LJ, Glennie L, Audrey S, et al. The health, social and educational needs of children who have survived meningitis and septicaemia: the parents' perspective. BMC Public Health 2013;13:954.

14 Williams CN, Eriksson C, Piantino J, et al. Long-term sequelae of pediatric neurocritical care: the parent perspective. J Pediatr Intensive Care 2018;7:173.

15 European Centre for Disease Prevention and Control (ECDC, 2017). Meningococcal disease. Available: https://www.ecdc.europa.eu/en/ meningococcal-disease [Accessed 24 Sep 2020].

16 Moreira $\mathrm{H}$, Frontini R, Bullinger $\mathrm{M}$, et al. Family cohesion and healthrelated quality of life of children with type 1 diabetes: the mediating role of parental adjustment. J Child Fam Stud 2014;23:347-59.
17 Als LC, Picouto MD, Hau S-M, et al. Mental and physical well-being following admission to pediatric intensive care. Pediatr Crit Care Med 2015;16:e141-9.

18 Scanferla E, Fasse L, Gorwood P. Subjective experience of meningitis survivors: a transversal qualitative study using interpretative phenomenological analysis. BMJ Open 2020;10:e037168.

19 Commission Nationale de l'Informatique et des Libertés (CNIL). Loi Informatique et Libertés, 2019. Available: https://www.cnil.fr/fr/la-loiinformatique-et-libertes [Accessed Sep 2020].

20 Article L1121-1 of the French public health code. Available: https:// www.lexology.com/library/detail.aspx?g=8dd39326-ea9f-44d6-a752 3a5b4c9af890 [Accessed Sep 2020].

21 Smith JA, Shinebourne P. Interpretative phenomenological analysis. American Psychological Association, 2012.

22 Fossey E, Harvey C, McDermott F, et al. Understanding and evaluating qualitative research. Aust $N Z J$ Psychiatry 2002;36:717-32.

23 Doupnik SK, Hill D, Palakshappa D, et al. Parent coping support interventions during acute pediatric hospitalizations: a meta-analysis. Pediatrics 2017;140:e20164171.

24 Tedeschi RG, Calhoun LG. Posttraumatic growth: conceptual issues. In: Calhoun LG, Tedeschi RG, eds. Positive changes in the aftermath of crisis. Mahwah: Lawrence Erlbaum Associates, Inc. Publishers, 1998: 1-22.

25 Wilson C, Cook C. Ambiguous loss and post-traumatic growth: experiences of mothers whose school-aged children were born extremely prematurely. J Clin Nurs 2018;27:e1627-39.

26 Beesley SJ, Hopkins RO, Francis L, et al. Let them in: family presence during intensive care unit procedures. Ann Am Thorac Soc 2016;13:1155-9.

27 Dudley N, Ackerman A, Brown KM, et al. Patient- and familycentered care of children in the emergency department. Pediatrics 2015;135:e255-72.

28 Darcy Mahoney A, White RD, Velasquez A, et al. Impact of restrictions on parental presence in neonatal intensive care units related to coronavirus disease 2019. J Perinatol 2020;40:36-46.

29 Giannini A, Miccinesi G, Leoncino S. Visiting policies in Italian intensive care units: a nationwide survey. Intensive Care Med 2008;34:1256-62.

30 Meert KL, Clark J, Eggly S. Family-centered care in the pediatric intensive care unit. Pediatr Clin North Am 2013;60:761-72.

31 Horikoshi Y, Okazaki K, Miyokawa S, et al. Sibling visits and viral infection in the neonatal intensive care unit. Pediatr Int 2018;60:153-6.

32 Oczkowski SJ, Mazzetti I, Cupido C, et al. The offering of family presence during resuscitation: a systematic review and metaanalysis. J Intensive Care 2015;3:41.

33 Longueville V. La visite de l'enfant en réanimation adulte : une visite préparée. Médecine Intensive Réanimation 2016;25:597-603.

34 Ministère de la Santé. Available: https://solidarites-sante.gouv.fr/ systeme-de-sante-et-medico-social/parcours-de-sante-vos-droits/ bonnes-pratiques-en-region/provence-alpes-cote-d-azur/article/ accueil-des-enfants-visiteurs-en-service-de-reanimation 